$\infty$

0

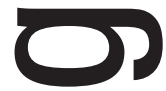

-

ת

1

$\longrightarrow$ 



\title{
AS INFLUÊNCIAS DA FILOSOFIA NATURAL E DA NATURPHILOSOPHIE NA CONSTITUIÇÃO DO DARWINISMO: ELEMENTOS PARA UMA FILOSOFIA DA GEOGRAFIA FÍSICA MODERNA
}

\author{
THE INFLUENCE OF THE NATURAL PHILOSOPY AND THE NATURPHILOSOPHIE IN THE CONSTITUTION OF THE \\ DARWINISM: ELEMENTS FOR ONE PHILOSOPHY OF THE MODERN PHYSICAL GEOGRAPHICAL
}

\section{LA INFLUENCIA DE LA FILOSOFÍA NATURAL Y DE LA CONSTITUCIÓN DE NATURPHILOSOPHIE DARWIN: ELEMENTOS PARA UNA FILOSOFÍA DE GEOGRAFÍA FÍSICA MODERNA}

\author{
Antonio Carlos Vitte - Universidade Estadual de Campinas (SP) \\ vitte@uol.com.br
}

\begin{abstract}
Resumo
Esse trabalho argumenta que a teoria da evolução de Charles Darwin sofreu forte influência da naturphilosophie de Schelling e Hegel, representando um avanço positivo nas concepções de teleologia da natureza. Fortemente influenciado pelas obras de Alexander von Humboldt, de Werner e pelas pesquisas no campo da paleontologia, a Teoria da Evolução, concebeu a transformação dos organismos e a sua especiação a partir determinantes geográficos e temporais. Ideologicamente influenciado por Lyell, que acreditava na hipótese da vera causa, Darwin relegou a matriz espacial e concentrou suas argumentações nas mudanças temporais, basicamente climáticas, como determinante da evolução. Os impactos da teoria da evolução atingem tanto o campo da geografia física, quanto da geografia humana, influenciando fortemente na postura metodológica das pesquisas geográficas, mas chamando a atenção para a complexidade das relações entre 0 espaço $\mathrm{e}$ tempo que estão em constante mudança.
\end{abstract}

Palavras-chave: Darwinismo. Naturphilosophie. Teoria da evolução. Espaço. Geografia física.

\begin{abstract}
This paper argues that the theory of evolution of Charles Darwin suffered from the strong influence of Schelling and Hegel naturphilosophie, representing a positive move in conceptions of teleology in nature. Strongly influenced by the works of Alexander von Humboldt, the Werner and the research in the field of paleontology, the theory of evolution, conceived the transformation of bodies and their speciation from spatial and temporal determinants. Ideologically influenced by Lyell, believed that if the vera causa, Darwin relegated the matrix space and focused its arguments on the changes in time, basically change, as a determinant of development. The impacts of the theory of evolution affect both the field of physical geography, as the human geography, strongly influencing the geographical position of the research methodology, but drawing attention to the complexity of the relationship between space and time are in constant change.
\end{abstract}

Key-words: Darwinism. Naturphilosophie. Theory of Evolution. Space. Physical geography.

\section{Resumen}

Este documento sostiene que la teoría de la evolución de Charles Darwin sufrió la fuerte influencia de Schelling y Hegel naturphilosophie, lo que representa un paso positivo en las concepciones de la teleología en la naturaleza. Fuertemente influido por las obras de Alexander von Humboldt, la Werner y la investigación en el campo de la paleontología, la teoría de la evolución, concibió la transformación de los organismos y su especiación espacial y temporal de los factores determinantes. Influenciado ideológicamente por Lyell, estima que si la vera causa, la matriz de Darwin relegado es-

\begin{tabular}{|l|c|c|c|c|c|c|}
\hline Boletim Goiano de Geografia & Goiânia - Goiás - Brasil & v. 29 & n. 1 & p. 13-32 & jan. / jun. & 2009 \\
\hline
\end{tabular}


pacio y centró sus argumentos sobre los cambios en el tiempo, básicamente el cambio, como factor determinante del desarrollo. Los impactos de la teoría de la evolución afectan tanto a la esfera de la geografía física, como la geografía humana, que influyen fuertemente la posición geográfica de la metodología de la investigación, sino llamar la atención sobre la complejidad de la relación entre el espacio y el tiempo están en constante cambio.

Palabras clave: Darwin. Naturphilosophie. Teoría de la evolución. Espacio. Geografía física.

\section{Introdução}

Nesse ano de 2009, comemoramos 200 anos de nascimento de Charles Darwin (1809-1888) e os 150 anos da publicação de sua obra célebre, A Origem das Espécies (DARWIN, 1981), tornando-se um verdadeiro paradoxo na ciência, pois ao mesmo tempo em que a Teoria da Evolução permitiu o desenvolvimento da moderna biologia, com impactos na medicina e na biotecnologia, as suas ideias provocam ainda, em 2009, um mal-estar na civilização, ao ponto de nas últimas décadas assistirmos a um revigoramento das teses criacionistas que vêm questionando o uso da Teoria da Evolução nas escolas. "Assim como Copérnico retirou a Terra do centro do universo, o universo darwinista destruiu o homem como epicentro do mundo natural" (STIX, 2009, p.28).

Não é demais frisar que o livro A Origem das Espécies foi publicado em 24 de novembro de 1859, ano que coincide com a morte dos dois grandes geógrafos que exerceram forte influência em Charles Darwin, Alexander von Humboldt, falecido em 6 de maio de 1859 e Karl Ritter, falecido em 28 de setembro de 1859.

É inegável o impacto das formulações darwinianas e de seus seguidores nas ciências de um modo geral. No caso da Geografia, em especial, podemos citar os trabalhos de Claval (1974), Capel (1982), Stoddart (1986), autores que mais diretamente trataram da influência do darwinismo na Geografia.

Para Claval (1974, p.48-49), o trabalho de Darwin promoveu um profundo recrudescimento metodológico na Geografia, particularmente na geografia humana, fornecendo um método para a análise científica da sociedade e dos agrupamentos humanos. Para Claval (op.cit.), Darwin demonstrava o papel do meio enquanto motor da evolução, que ocorria a partir de uma luta constante entre os organismos, sendo esse o motor da vida. Ainda para o autor (CLAVAL, op.cit.), o evolucionismo desenvolvido a partir das teses darwinianas colocava-se como método e, ao mesmo tempo, permitia a abordagem histórica da sociedade. Fato que também é corroborado por Stoddardt (1986, p.158-159), que além de fornecer o método de análise, as reflexões de Darwin propiciaram o desenvolvimento da geografia física, na 
medida em que os processos passaram a ser compreendidos como contínuos e que se ocorrem ao longo do tempo, perspectiva que produz uma série de transformações na paisagem. Essa concepção, segundo Stoddardt (op.cit.), foi motivada pelo princípio da preservação da raça e a luta do mais forte e de outro lado pelo princípio da causalidade newtoniana, que permitiram o desenvolvimento da Geografia como um todo.

Para Capel (1982), o evolucionismo converteu-se em uma grande síntese explicativa da realidade e permitia articular o conhecimento científico produzido pelas demais ciências, com forte impacto na sociologia de Spencer e na Antropogeografia de Ratzel.

No entanto, a nosso ver, apesar dessas sérias e importantes contribuições à história da Geografia, essas análises carecem de um maior aprofundamento, no sentido de se buscar uma estrutura epistemológica que não seja necessariamente marcada por uma ruptura, mas a possibilidade de entendermos a história das ideias e sua matriz resultante a partir de um jogo tenso entre épocas e posições, muitas vezes dadas como contraditórias.

É nesse sentido, que o objetivo do presente trabalho é discutir as influências da filosofia natural e da naturphilosophie na constituição do darwiniano. Como complemento, e não menos importante, objetivamos discutir as influências do darwinismo no desenvolvimento da geografia moderna. Com isso, pretendemos colaborar para a construção da filosofia e da epistemologia da geografia, particularmente da geografia física, ao mesmo tempo, contribuir para o atual momento sobre a rediscussão sobre o significado da natureza e da superfície da Terra.

\section{Uma questão de balizamento epistemológico para a (re) construção histórica da filosofia da geografia}

Nos últimos tempos, é comum ouvirmos autores dizerem que a epistemologia está morta, ocorrendo ao mesmo tempo um fortalecimento da filosofia pragmática, principalmente na geografia física.

Uma das possibilidades do recuo pragmatista no pensamento tenha sido talvez aberto por Hume, no século XVIII, para quem não haveria conhecimento possível além da experiência. Para Hume, o conhecimento é o produto de nosso hábito, e a investigação científica deve necessariamente estar vinculada às operações que nossa mente realiza para criar o hábito e sua repetição. Assim, para Hume, não haveria nenhuma relação, ou antes, 
conexão entre o passado e o futuro. Esse postulado teve forte impacto no século XX, na psicologia behaviorista, assim como na abordagem sociológica de Khun, no naturalismo holista de W.V. Quine e no pragmatismo wittegensteiniano de Richard Rorty. Isso não significa que esses autores sejam necessariamente vinculados ao ceticismo humeano, mas seus argumentos são facilmente remontados a ele.

Outra interpretação epistemológica, e que nega a matriz humeana, é a ligada à filosofia transcendental de Kant. A questão é superar a interpretação epistemológica principalmente como formulada por Foucault (1970), admitindo a possibilidade de que haveria ganho real de conhecimento quando há transição de uma visão de mundo para outra, e de que esse ganho pode ser avaliado racionalmente. Há aí um problema sério, que é uma deficiência do pragmatismo, pois quer tornar o que quer que ocorra no passado irrelevante para o que quer que venha a ocorrer em um tempo posterior.

Embora não façamos objeção a proposta de Foucault (1970), a qual seja, a de "trazer à luz" as condições de possibilidade de nossas alegações de conhecimento, acreditamos que o conhecimento científico que consiste em um conjunto de proposições teóricas, que podem se revelar verdadeiras ou falsas, acrescido do conjunto não explicitado de concepções metateóricas ou mesmo metafísicas, constituem o "pano de fundo" dessas proposições. Esses dois conjuntos se articulam em um único bloco, quando um determinado bloco desmorona, como o aristotélico no século XVII, por exemplo, ou o bloco criacionista no século XIX, representado por Cuvier, é possível que uma ou outra de suas partes, isto é, algumas das referidas concepções metateóricas e uma ou outra proposição teórica que tenha resistido, se desprenda e venha, posteriormente, a se acomodar em algum outro lugar. Um exemplo para esse trabalho é o das mudanças evolutivas, que irão gerar a emergência de novos problemas e que no caso da Geografia, serão mesclados com resíduos de concepções tidas como ultrapassadas, mas que serão importantes para a consolidação de modos explicativos e interpretativos da realidade.

\section{Questões antecedentes e fundantes da interpretação evolucionista}

É comum e verdadeiro afirmarmos que em 1859, quando saiu a primeira edição do livro Origem das Espécies, a humanidade ainda acreditava que a Terra havia sido criada há 6.000 anos e que as maravilhas da natureza eram a manifestação do dom de Deus. No entanto, devemos relativizar essa 
crença, pois desde o século XVIII, um amplo debate na comunidade científica e filosófica vinha se desenvolvendo, e que sem sombra de dúvida, culminou nas reflexões de Darwin e com fortes impactos na Geografia.

Nesse contexto, as interpretações sobre uma mesma causa, mecanismo ou mesmo sobre um princípio foram as mais variadas possíveis e, na maior parte das vezes, conviveram conjuntamente e com influências mútuas. É o caso do mecanicismo que recebia um tipo de tratamento por parte de Boyle, que era totalmente diferente do mecanicismo praticado por Lamarck, que por sua vez era diferente do mecanicismo praticado pelos naturalistas e filósofos da Naturphilosophie (MAYR, 1998). Assim, enquanto que na Inglaterra predominava a interpretação empirista fundamentada na teologia natural, na Alemanha, as discussões sobre a vida e a natureza eram fundamentadas pela Naturphilosophie (MAYR, 1998, p.132-3).

As interpretações eram múltiplas, assim como múltiplas eram as geografias e as biologias praticadas na Europa até o século XIX, quando a síntese darwiniana e a ratzeliana irão cada qual, a seu modo, unificar os seus objetos e suas epistemologias.

No rico processo de constituição da modernidade e do mundo, a nossa opção é pela Naturphilosophie, ou seja, a nossa hipótese é que o darwinismo é o resultado de um processo que se iniciou com a teleologia da natureza, onde a noção de organismo foi fundamental para estruturar um novo modo de se conceber a natureza e o mundo.

Participação importante nesse processo foi a da concepção histórica de natureza, desenvolvida por Kant em sua Crítica da Faculdade do Julgar (KANT, 1995), que organizou o status epistemológico para uma história da natureza e para uma descrição da natureza, onde a geografia física funcionou como uma idéia regulativa sobre a concepção de Terra e de Mundo, culminando nos trabalhos de Werner e Buffon sobre uma ciência históriconatural, cujo representante seria a geologia e a geografia física; interferindo no programa da Naturphilosophie sobre a história da natureza, com a teoria da terra e dos animais.

Isso foi possível a partir de uma concepção teleológica de natureza, que funcionou como regulativa e como princípio heurístico, permitindo assim conhecer, de um lado, o organismo, e de outro, o mundo enquanto uma totalidade orgânica passível de ser conhecido pela experiência.

A partir dessa formulação, o organismo foi considerado uma forma que apresenta alterações resultantes do arranjo de suas partes, que são co- 
erentes e integradas entre si. O organismo, enquanto totalidade para a experiência, está harmoniosamente organizado em várias escalas. Para Kant, o organismo e o mundo são um sistema organizado de leis e mediado pela totalidade, havendo conexões entre as leis particulares e as universais, assim como, empiricamente entre as partes dos organismos. Assim, o organismo e o mundo são unidades sistemáticas, empíricas, com uma finalidade. Para Kant, a teleologia é uma categoria essencial para explicar o funcionamento do mundo, dos organismos, sendo também um princípio regulativo para se compreender a evolução dos organismos e das espécies.

Derivado dessas concepções da Crítica do Juízo (KANT, 1995) e influenciado pelo primeiro movimento romântico, particularmente pelos irmãos Schelegel, August Wilhelm (1767-1845), e Friedrich (1772-1829) e também por Caroline Michaelis (1763-1809) conhecida como a força erótica do Círculo Romântico, Johann Friedrich Blumenbach (1752-1840) irá desenvolver o princípio da Bildungstrieb, também conhecido como Nexus Formativus (BLUMEMBACH, 1781) tendo por base a concepção epigência de geração da vida. Com essa concepção, está criada a noção ontogênica do organismo, formando assim, as matrizes da embriologia.

No princípio da Bildungstrieb, um ser, uma vida é o produto do encontro de dois gametas radicalmente diferentes entre si, que geram um terceiro ser totalmente diferente de seus progenitores. Para Blumembach, a Bildungstrieb é a responsável pela reprodução e pelo desenvolvimento do organismo a partir de modificações de interconexões de suas partes. A Bildungstrieb reescreve o mecanicismo, cujo produto é o teleomecanicismo. Fundamentando-se em um princípio heurístico que é a teleologia kantiana e que, baseado no princípio evolutivo de Haller (1708-1777), passa a conceber a possibilidade de variações de tipos e variedades (espécies) na natureza, entendendo isso como uma possibilidade teleológica de evolução dos corpos organizados (RICHARDS, 2002).

Outro conceito importante, e que exercerá forte influência em Herder, será o de Lebenkraft, que diz respeito ao papel do meio físico no desenvolvimento do organismo e das espécies. Para Blumembach, o meio natural, particularmente o clima e a oferta de alimentos, poderia causar degeneração das espécies, com hibridização das mesmas, criando novos tipos de organismos (espécies), provocando assim uma degeneração da espécie com a formação de novos tipos.

As concepções de Bildungstrieb e de Lebenkraft exerceram poderosa influência nas ciências naturais, demonstrando claramente a possibilidade de produção de novas espécies (BLUMEMBACH, 1781, p.88). Outra influên- 
cia marcante foi nos filósofos da Naturphilosophie , particularmente em Herder, Schelling e Goethe, com forte interferência na Ciência Humboldtiana e no consequente nascimento da geografia física moderna, particularmente em seus conceitos de paisagem e geoesfera.

Johann Gottfried Herder (1744-1803) utilizou os conceitos acima para a elaboração de sua interpretação histórica sobre a evolução da Terra e das culturas humanas, requalificando o conceito de espaço kantiano. Por sua vez, em Friedrich Schelling (1775-1854) os conceitos de Bildungstrieb e de Lebenkraft, associados aos processos teleológicos, serviram para fundamentar a análise dos fenômenos naturais e fundamentar suas leis, particularmente na natureza orgânica. A partir desses conceitos, Schelling criou a noção de arquétipo (Urbilde), que gradualmente se desenvolveria em espécies e tipos biológicos, de formas inorgânicas para orgânicas em um processo contínuo de transformação das espécies (RICHARDS, 2002).

Na cabeça do gênio Johann Wolfgang von Goethe (1749-1832), os conceitos de Blumembach ganharam asas e permitiram o desenvolvimento de Bildung não mais com uma visão teológica e fundamentada na força vital como em Herder, mas enquanto amálgama que permite ao mesmo tempo discutir Ciência fazendo Arte, e Arte ao realizar experimentos científicos. Ou seja, para se conhecer a natureza, deve-se estar embuído de concepções experimentais, teleológicas e estéticas (VITTE, 2008).

De Goethe, a natureza agora dinâmica e não determinística emergirá enquanto totalidade que se materializa em formas, em morfologias, a partir de um arquétipo, e que se desenvolvem no tempo e no espaço em processos contínuos de transformação-criação-destruição, em uma constante metamorfose dos organismos.

Um dos exemplos mais claros de interferência direta das concepções de Goethe no desenvolvimento da geologia e da geografia física refere-se ao primeiro período de Weimar, em que Goethe trabalhou como superintendente de minas e observou atentamente a geologia de diversas regiões. Nesse trabalho, contou com a colaboração de dois jovens estudantes de Freiburg, Johann Carl Wilhelm Voigt (1752-1817) e Abraham Gottlob Werner (17501817), que futuramente tornar-se-iam os geólogos mais importantes da Alemanha (RICHARDS, 2002). Goethe encarregou os jovens estudantes de realizarem o levantamento geológico do território e depois realizarem conjuntamente pesquisas mais detalhadas, o que levou Goethe a refletir sobre a beleza natural das formas de relevo e especulações mais específicas sobre os processos geológicos (GOETHE, 1988). 
Em 1784, refletindo sobre a origem do granito e acompanhando o acalourado debate entre neptunistas e wernerianos sobre a origem das rochas, Goethe apoiou os wernerianos, assumindo que a Terra formou-se em condições fluidas com o crescimento interno dos minerais, formando uma enorme montanha (Arquétipo) que posteriormente foi erodida, cujos detritos formaram rochas secundárias e ao mesmo tempo esculpindo a plasticidade das morfologias da Terra (GOETHE, 1977).

Pelo exposto, pode-se perceber que ao contrário do que clamam os grandes manuais de história da geografia, o período que antecedeu a Origem das Espécies, de Darwin, foi marcado por um profundo debate e reflexões médicas e biológicas, fundamentadas em uma concepção cosmológica e metafísica de vida e de natureza (RICHARDS, 2002).

\section{Charles Darwin e a ruptura da natureza}

Segundo Secord (2000), a obra darwiniana é o produto da Inglaterra Vitoriana, em que pouco antes da publicação da obra seminal de Darwin, $A$ Origem das Espécies, em 1859, o debate que predominava entre a intelectualidade era sobre a possibilidade de se localizar os vestígios da Criação. Para o autor (SECORD, op.cit), esse é um dos principais momentos (SECORD, op.cit.) em que ocorreu a criação da chamada história natural. É assim, que, no período vitoriano, a intelectualidade procurava os vestígios da Criação, onde a geologia poderia fornecer elementos científicos que comprovassem os escritos bíblicos. Muito embora o ambiente fosse dominado pela filosofia mecânica e houvesse uma clara concepção de que a geologia enquanto ciência era o produto da revolução industrial, a história da natureza estaria, assim mesmo, subordinada à mente de Deus.

Para Secord (2000, p.170) a moderna ciência da natureza é o produto de uma sociedade urbana, metropolitana, em que a aristocracia inglesa projetava na natureza o seu próprio ego. E, em 1840, essa filosofia natural estava associada a um conflito social e religioso, particularmente com os ideais socialistas de Robert Owen, desenvolvendo-se no contexto político, religioso a concepção conservadora Unitariana, não distinguindo os milagres das leis naturais, mas mantendo o status quo social (SECORD, 2000, p.204-5). É o momento em que a doutrina malthusiana é dominante e fornece elementos políticos e ideológicos para a sociedade urbana e industrial.

A partir desse momento, ocorre um revigoramento dos estudos da na- 
tureza, vinculados agora à concepção unitariana de vida, mantendo o domínio da teologia natural sob o controle da igreja. Assim, em Oxford, a geologia, a química e a botânica passaram a ser opcionais, tendo o seu corpo docente reduzido, enquanto que o ensino de teologia dominava o curriculum. Já em Cambridge, por volta de 1840, o ensino de matemática predominava no curriculum, juntamente com o ensino de teologia natural sob controle da igreja anglicana (SECORD, 2000, p.227-8). A metáfora que predominava era a do livro da criação, da arquitetura do mundo, da ordem e da felicidade doméstica na Terra (SECORD, 2000, p.102).

Epistemológica e metodologicamente, aceitava-se, na Inglaterra vitoriana, a vera causa como estrutura explicativa. Ou seja, para Newton, toda pesquisa e toda explicação tinha um limite, uma existência real que governava a natureza última das coisas. Daí, toda pesquisa científica deveria ser estruturada pela indução e nunca pela hipótese, pois a comprovação dependia de uma existência independente da causa e da teoria. Na época de Darwin na universidade, o maior representante da pesquisa científica era John Herschel, que considerava, para a realização de uma pesquisa, a atenção para o fato de que na natureza havia uma grande multiplicidade de efeitos, que indicavam a possibilidade de várias causas, diversos efeitos e muitas causas que poderiam ser semelhantes às causas verdadeiras. Herschel chamava isso de virtudes plásticas da natureza. Para não se confundir, Herschel propunha a observação direta e a inferência do fenômeno. Com isto, Herschel elaborou uma concepção uniformitariana da natureza, onde se pudesse ter uma visão do passado, possibilitando ao pesquisador inferir as causas que atuaram no passado, auxiliando o pesquisador a inferir causas de outras causas da mesma espécie, mas nunca causas de diferentes espécies.

É nesse contexto que Charles Robert Darwin (1809-1888) irá realizar sua formação universitária e científica. Talvez seja por esse motivo que apenas em 1937 Darwin tenha se definido como "filósofo naturalista", ou seja, após sua viagem a bordo do Beagle (1831-36).

Darwin realizou o seu curso universitário em Edimburgo, em 1825, chamada aquela época de "Atenas do Norte", devido ao fervilhar do iluminismo, onde perdurava uma concepção materialista de vida e matéria e a noção de transformação das espécies. Foi fortemente influenciado por Henslow, mineralogista e que acreditava na migração dos continentes. É o momento do fervilhar das concepções de Hutton, que era ardentemente difundido por Thomas Hope, químico galvanista e que introduz Darwin nos 
mistérios da geologia, realizando trabalhos de campo nos arredores de Edimburgo. Ao mesmo tempo, 1826, Darwin entra em contato com o professor Grant, anatomista comparativo que o apresenta as ideias de Lamarck, para quem as plantas e os animais atuais existiriam através de processos naturais de transformação, mudanças adaptativas, que os tornariam cada vez mais complexos. Para Lamarck, isso era devido as mudanças de hábito e uma resposta às alterações ambientais.

Em 1831, já em Cambridge, Darwin conhece o reverendo professor John Henslow que fora professor de mineralogia durante cinco anos e depois se tornara professor de botânica de 1827 a 1861. Henslow, em 1819, juntamente com o reverendo professsor Adam Sedgwick, geólogo e inspetor chefe da universidade, fundaram o Cambridge Philosophical Society, voltada para os estudos de geologia, mineralogia e botânica, que eram regradas por atividades de campo nos arredores da universidade. (KEYNES, 2004, p. 34-5). Darwin participou desse grupo de 1829 a 1831. Nessa sociedade, Darwin participou de atividades de campo voltadas ao mapeamento geológico com Sedgwick, especialista em mapeamento e reconhecimento de padrões regionais. Desses campos, Darwin tirou uma das mais importantes lições científicas que o acompanharia pelo resto da vida, a qual seja, realizar muitas observações, coleta de dados empíricos e ser cético com as informações (KEYNES, 2004, p.38).

Em 1831, Darwin conhece John Herschel, astrônomo e biogeógrafo que lhe apresenta as obras de Alexander Von Humboldt, particularmente a obra "Viagens à América Equinocial". Sendo essa a maior influência científica em Darwin, que através de Humboldt, torna-se um verdadeiro cientista natural e é introduzido na metodologia científica, onde conhece o papel da indução e o papel da observação da paisagem.

O impacto da obra humboldtiana foi tamanho que Darwin organizou um grupo de estudos sobre as obras de Humboldt e chegou a planejar com amigos uma viagem às ilhas Canárias para examinar o cone vulcânico do pico de Teide, em Teneriffe, que havia sido observado por Humboldt em 1799. Afora a influência de Humboldt, Darwin recebe influências da geologia, particularmente com as concepções de Hutton e de Werner sobre a evolução da Terra e dos sistemas deposicionais.

Em Humboldt, Darwin entra em contato com uma concepção de natureza dinâmica e que está sempre sujeita à transformação. Forma-se a concepção de que é necessário ao cientista natural desenvolver uma concepção holística de ciência e de mundo natural e que os fenômenos são sempre interconectados. 
Humboldt foi fundamental para a tese darwinista da evolução das espécies, pois a ciência humboldtiana trazia consigo que a experiência estética era a responsável pela organização da matéria bruta, que se realizava em rochas, na distribuição espacial e na relação das plantas e dos animais para com as diferentes regiões do globo. Ou seja, Humboldt colabora com Darwin na medida em que epistemologicamente constrói a noção de que existe um sistema da natureza e que a vida deve ser compreendida nesse sistema dinâmico.

Outra referência importante, e que será fundamental para Darwin e para a estruturação da geografia física, será Charles Lyell, que com seus "Princípios de Geologia", com sua visão de geologia histórica e do princípio do "uniformitarismo", mais a concepção paleontológica do geólogo Sedgwick, auxiliarão Darwin na montagem do sistema explicativo para a Teoria da Evolução das Espécies, pois a despeito da variabilidade geográfica, as causas atuantes no presente serão sempre as mesmas e com a mesma intensidade e causalidade. Segundo Deswmond e Moore (1995), o princípio do uniformitarismo de Lyell fora elaborado para combater a concepção dialética de natureza de Hegel, fato que colocaria a sociedade vitoriana em confronto com as reinvidicações operárias que estavam em curso na Inglaterra.

Porém, para Wool (2001), Anderson (2007) e Virgili (2007), Charles Lyell (1797-1875) pode ser considerado o fundador da geologia moderna, onde o seu famoso livro Princípios de Geologia, publicado entre 1830 e 1832, é o produto de intenso empirismo, fruto de trabalhos de campo na França, Espanha, Itália e América do Norte. Nessa obra, Lyell desenvolve o princípio do uniformitarismo como estratégia para combater o catastrofismo, também chamado de supernaturalismo. Segundo Lyell, os dados geológicos podem ser interpretados a partir do princípio de forças e de causalidade. Com isso, Lyell insere a observação e a experimentação na explicação geológica.

Uma das grandes contribuições do uniformitarismo ao desenvolvimento da geologia e da geografia física, com forte impacto em Darwin, foi o fato de Lyell conceber a vida na Terra como o produto de uma grande interação e interdependência entre os organismos e o ambiente, recuperando os conceitos de Bildungstrieb e de Lebenkraft de Blumembach e aplicando-os à geologia. No entanto, Bueno-Hernándes e Llorente-Bousquets (2006), apontam que o uniformitarismo estruturou-se pois Lyell acreditava na vera causa como princípio metodológico, pois estava fortemente ligado ao newtonianismo.

Nos Princípios de Geologia, Lyell trata das variações climáticas globais, das erupções vulcânicas, da erosão dos solos e de seu transporte, com a formação de deltas e praias. Mas trata também dos fósseis e da distribuição 
dos animais no globo, observando que as mudanças biológicas e ambientais promovem a formação de fósseis nos estratos geológicos, ao contrário do que pensavam os catastrofistas (LYELL, 1832).

Para Rudwick (1970) no princípio do uniformitarismo estão incluídas duas premissas, uma metodológica e outra ontológica. Pois o uniformitarismo representa: a) uma uniformidade das leis; b) uniformidade dos processos; c) uniformidade do ritmo o gradualismo; d) uniformidade da estabilidade. As duas primeiras premissas são metodológicas e referem-se ao princípio da indução e da simplicidade. Já o gradualismo e a estabilidade são premissas ontológicas, pois pressupõem que o funcionamento da Terra depende de princípios empíricos.

O trabalho de Lyell é o ideal metodológico newtoniano, pois a explicação fundamenta-se na vera causa, rejeitando a hipótese, reconhecida pelos newtonianos como especulação. Uma influência marcante em Lyell é John Herschel, que com sua metodologia da vera causa, não permitia conjecturas e teorizações, criando assim, no dizer de LAUDAN (1987, p.216) uma fina aderência na metodologia indutiva. Lyell justificou a metodologia científica de Herschel e desenvolveu a geologia moderna, em que a estrutura chave foi o uniformitarismo. Herschel considerou o livro Princípios de Geologia, de Lyell, um brilhante exemplo de aplicação da metodolgia da vera causa na geologia (HERNÁNDEZ \& BOUSQUETS, 2006; LAUDAN, 1987, p.217).

Outro ponto importante abordado por Lyell, que influenciará a geografia física e os trabalhos de Darwin, diz respeito à importância do tempo na esculturação da superfície da Terra e na distribuição dos fósseis na Terra. Lyell descreve o papel das geleiras na esculturação das formas de relevo e no transporte de rochas, como o granito, que não existe em muitas localidades e que se utilizava explicação sobrenatural para ele.

Os Princípios de Geologia têm grande contribuição para a biogeografia, na medida em que Lyell utiliza o raciocínio de que mudanças no clima e na proporção de massas da Terra afetariam a erosão e a sedimentação ao longo do tempo, sendo responsável pela desigual distribuição biogeográfica das espécies, onde o clima era considerado como sendo o fator principal para a distribuição dos animais e para a esculturação da Terra, pois Lyell não havia encontrado evidências empíricas do oceano primitivo (LAUDAN, 1982, p. 237).

Já para Wool (2001), uma das maiores contribuições de Lyell na formulação da Origem das Espécies, de Darwin, foi a noção de tempo, que permitiu a Darwin construir seu princípio de seleção natural e especiação. 
Para Ruse (2005), a ruptura provocada pela Origem das Espécies, de Darwin, é uma mudança nas metáforas explicativas da natureza, na medida em que estabeleceu que a causa força da evolução das espécies é a seleção natural. Para o autor (RUSE, op.cit.), Darwin transportou a noção de natureza como máquina para o organismo, demonstrando que os organismos apresentam leis. Metodologicamente, Darwin desenvolveu uma teoria naturalista par excellence e o seu conceito de seleção natural seria a conexão através da qual as causas são efetivadas, onde a seleção natural seria o grande mecanismo. Ainda segundo Ruse (2005, p. 294), Darwin, ao contrário de Herschel e Whewell, conseguiu preservar a tradição de Boyle, na medida que concebeu a natureza como uma rede sistemática de leis governada por eventos, o que segundo Asa Gray, garantiria a história da natureza.

Para Depew (2008), a ruptura produzida por Darwin é o produto de uma concepção teleológica de natureza, fundamentada na Naturphilosophie, e um retrabalhamento da concepção teleológica de Aristóteles. Essa teleologia estaria garantida pelo princípio de seleção natural e pela adaptação, que garantiria o sucesso reprodutivo da espécie, o que obrigou Darwin a rever o princípio da causalidade para explicar a adaptação. A adaptação ocorre em função do ambiente, que dependendo das variações, pode reter ou acelerar a reprodução.

A partir das críticas de Asa Gray e de Lyell, Darwin passou a rever a sua concepção teleológica e passou a assumir uma posição neo-platônica, com o essencialismo tipológico, fruto de influências da Naturphilosophie, incluindo o essencialismo tipológico em uma espécie de cosmologia aristotélica, transformando o conceito aristotélico de substância para organismo, que assumiria a estrutura metafísica para a explicação da natureza (LENNOX, 1994; FALCON, 2006).

Nessa estrutura metafísica e cosmológica, Darwin passou a considerar que o organismo se realiza em espécies específicas e em um determinado nicho ambiental, cujas espécies são distribuídas em uma scala naturae, transportando assim a noção de telos aristotélico para a relação entre o organismo e seu ambiente (FALCON, 2006).

Darwin passou a considerar a noção de arquétipo como a elaborada pela Naturphilosophie, particularmente por Goethe, e passou a considerar a concepção de natureza como dinâmica a partir de um balanço de forças de Schelling. Concepção que tanto encantou seu avô Erasmus Darwin (1731-1802) e que permitia justificar filosófica e cientificamente a evolução dos seres da natureza, sempre a partir de uma concepção de totalida- 
de. Princípio que influenciou Alexander von Humboldt que, por sua vez, iniciou Darwin na concepção de natureza e de experiência estética da natureza, obrigando-o a rever os princípios aprendidos com Herschel e com Henslow.

A teoria da evolução, como a formulada por Darwin, é um processo de construção mental e epistemológica fundamentado em um idealismo metafísico da qual participaram Schelling, Goethe e Humboldt, tendo nas concepções de teleologia e sublime de Kant, a base para argumentarem cientificamente a dinâmica evolutiva da natureza.

A nosso ver, a obra darwiniana não pode ser concebida apenas como o produto da sociedade e da ciência vitoriana, mas também de um complexo intercruzamento de várias influências, particularmente as desenvolvidas pela biologia da Naturphilosophie, pelas reflexões dos filósofos-da-natureza e pela metodologia newtoniana.

Mas a sua ligação consciente ou inconsciente com a causa vera, base do uniformitarismo, acabou por provocar uma fissura em Darwin demonstrada claramente na relação tempo - espaço, muito embora o espaço tenha sido uma estrutura chave para Lyell e mesmo para Darwin. A concepção newtoniana de espaço, enquanto categoria geométrica, que perdurou em Lyell, interferiu na resolução de problemas colocados pela crítica à Teoria da Evolução, muito embora a filosofia-da-narureza já tivesse redesenhado o conceito de espaço que, por exemplo, permitiu a Humboldt reinventar a superfície da Terra, ponto chave para o trabalho de Darwin na medida em que provocou uma ruptura na concepção de natureza.

Essa situação, a de não considerar o espaço em sua formulação nuclear, foi problemática para a própria Teoria da Evolução como para o desenvolvimento da Ciência Geográfica e, particularmente, para a geografia física.

\section{Impactos dos postulados darwinianos na interpretação geográfica do mundo}

Como já ressaltamos anteriormente, os postulados darwinianos destruíram a concepção vitoriana de mundo e de natureza, a tal ponto que Freud coloca Darwin no mesmo nível de Copérnico. Passamos a viver a melancolia de sermos apenas mais uma espécie na superfície da Terra e, que por sorte adaptativa, provocada principalmente por nosso engenho em desenvolver próteses tecnológicas, ainda conseguimos sobreviver.

Mas à parte esse pensamento melancólico, deve-se ressaltar que os postulados darwinianos provocaram uma enorme quantidade de possibili- 
dades interpretativas sobre o mundo e sobre possível resgate da auto-estima humana. Assim como o mecanicismo, os postulados darwinianos foram mesclados e fundidos a fragmentos conceituais e interpretativos do passado, passando a constituir um novo corpus interpretativo para o mundo. Ou seja, a sociedade de meados do século XIX buscou produzir sínteses interpretativas onde participaram lado a lado correntes aparentemente incompatíveis, como por exemplo a noção de pré-formação com a epigênese, o mecanicismo com o vitalismo, o deísmo com a teologia natural, o catastrofismo com o uniformitarismo, fato que chamou a atenção de Nietzche em A Genealogia da Moral (NIETZCHE, 1987).

Assim, devemos tomar cuidado com as reflexões sobre o impacto do darwinismo nas ciências humanas e na geografia em particular, o que significa que na história do pensamento geográfico, devemos tomar cuidado com o uso de raciocínios e conceitos gerais e simplistas.

Um exemplo de reação e busca de justificação dos postulados darwinianos e com forte impacto na geografia, particularmente na obra ratzeliana, é a reflexão filosófica monista empreendida por Ernest Haeckel (1834-1919). Aliás, Haeckel foi professor de F. Ratzel e seu grande incentivador, e Ratzel, influenciado por Haeckel, desenvolveu em sua primeira obra, um ensaio interpretativo darwiniano nos moldes do monismo de Haeckel (CLAVAL, 1974).

Haeckel, biólogo alemão, foi um importante defensor do darwinismo, sendo o primeiro naturalista a traçar uma árvore evolutiva. Fortemente influenciado pela Naturphilosophie e particularmente por Goethe, escreveu, em 1886, a obra Morfologia Geral, em que desenvolveu várias evidências do evolucionismo e trabalhou a relação entre ontogenia e filogenia, onde a filogenia é a causa mecânica da ontogenia, contribuindo assim para responder aos críticos de Darwin que o questionavam sobre a herança das características adquiridas (CASSIRER, 1993, p.215-7).

Haeckel propõe a teoria biológica do conhecimento (HAECKEL, 1904, p.1-23). Fundamentando-se em um ponto de vista monista, causal e teleológico, Haeckel em 1866 no tomo II do livro Morfologia Geral, afirma que "toda a ciência da natureza é filosofia e toda verdadeira filosofia é uma ciência natural" (HAECKEL, 1904, p.4), o que pressupõe a unidade da natureza e a unidade da ciência. Para Haeckel, um organismo não pode ser comparado a uma máquina, havendo uma unidade entre a natureza orgânica e inorgânica. Ambas estão sujeitas às leis evolutivas. A evolução inorgânica é comandada por leis físicoquímicas e a orgânica é parte da evolução do nosso planeta, e esta, uma parte imensamente pequena de evolução do universo (HAECKEL, 1904, p. 299). 
A filosofia monista de Haeckel exerceu forte influência em Ratzel, pois por questões políticas e territoriais, associadas ao forte impacto dos postulados positivistas e mecanicistas, mais o problema que os postulados darwinianos colocavam para os impérios, pois com o primado da competição e da evolução, colocava um problema sério para a manutenção política das extensas áreas coloniais.

É nesse contexto que F. Ratzel irá produzir sua Antropogeografia (RATZEL,1975), em que os primados da filosofia monista de Haeckel e sua concepção teleológica são transferidas para o Estado, emergindo dessa reflexão o papel do espaço e do território na construção da história. Uma das fortes críticas que eram dirigidas aos postulados darwinianos e tinham como pano de fundo a questão do espaço, lidas na época como condições geográficas da distribuição e evolução das espécies. Muito embora Darwin fosse expert em geologia, mas a concepção temporal, desenvolvida por Lyell, em função e seu credo na vera causa, no indutivismo e na concepção de espaço e de geografia física de Herschel, que em sua obra Pysical Geography of the Globe de 1861, afirmava sua crença em processos miraculosos para o surgimento gradual de novas espécies (HERSCHEL, 1861, p.12), procurando assim, adaptar as teses darwinianas ao seu modelo de ciência.

O espaço aparece como um sério obstáculo epistemológico (BACHELARD, 1996) para Darwin, na qual a filosofia monista de Haeckel, retrabalhada por Ratzel, que produzirá inclusive uma requalificação das teses darwinistas ao fundi-las com concepções neo-lamarckianas (LIVINGSTONE, 1992), acarretando uma nova concepção de espaço e de história, com forte influência em Mackinder.

Na geografia física, a questão do espaço e a tentativa de resolução desse obstáculo ao darwinismo foi resolvida a partir do trabalho de Thomas $\mathrm{H}$. Huxley, com sua obra "Fisiografia" (STODDART, 1986), em que a Evolução foi tomada em estágios pré-definidos, com velocidade variável e em seqüência, introduzindo a causalidade como princípio universal na explicação da geografia física, cujo recorte empírico passou a ser o regional-ecológico.

Essa construção metodológica e explicativa, que passou a ser o núcleo estruturador da geografia física, completou-se com os trabalhos de William M. Davis, particularmente com a "Teoria do Ciclo Geográfico da Erosão" (1899), em que Davis, retrabalhando a concepção evolucionista de Darwin, a partir de uma concepção neo-lamarckiana, influenciado por Agassiz , Shaler e Haeckel, propõe que a evolução por ciclos permite inclusive a preservação de características processuais e morfológicas. 
É o momento na formação da escola geográfica norte-americana de uma reconsideração do pensamento teológico e, principalmente, uma releitura teleológica da natureza, a partir de influências de Ratzel e de Ritter (LIVINGSTONE, 1992). Assim, o ciclo davisiano seria o produto de um momento histórico de consolidação da evolução darwiniana, mas com fortes influências do neo-lamarckismo e da teleologia ritteriana. Fato que garantiu em termos epistemológicos e metodológicos a possibilidade de estabelecer conexões estreitas entre o tempo e o espaço nos estudos geomorfológicos, segundo uma concepção de cosmos e integradora da natureza.

\section{Considerações}

O desenvolvimento do trabalho até aqui nos possibilita tecer algumas considerações:

a) A discussão que se coloca é de fundamental importância para o estudo da história e epistemologia da geografia, particularmente da geografia física, onde constituiu-se uma concepção de natureza cíclica e segundo um arranjo pré-definido. No atual momento histórico, em que as mutações no mundo e na natureza são fortes e intensas, o momento é propício para discutirmos as bases da geografia física e que natureza desejamos nessa nova geograficidade que está em construção.

b) Sob o ponto de vista epistemológico e metodológico, a noção de ruptura, dificultando a leitura e a construção das estruturas geográficas, dada a complexidade do período em que se formaram, na qual participaram várias tendências explicativas que se fundiram em um novo corpus teórico.

c) Assim, a nosso ver, não há uma linha clara e delimitada de ruptura entre a concepção teológica de natureza e a darwiniana de evolução, na geografia e na geografia física, ao contrário, a concepção de evolução, da natureza foi retrabalhada a partir de fragmentos da teleologia da natureza da Naturphilosophie, associada a leituras e releituras da filosofia monista, da causalidade newtoniana que foi reestruturada a partir da Crítica do Juízo de Kant. Importante frisar o papel do neo-lamarckismo na construção de modelos explicativos e interpretativos sobre a natureza 
na geografia física, o que torna complexo o trabalho de história da geografia física.

d) O espaço e o papel da distribuição geográfica foram um importante obstáculo epistemológico para Darwin, que muito embora influenciado por Humboldt e pela Naturphilosophie, ficou preso aos postulados temporais de Lyell, base do uniformitarismo, cujo princípio era a causa vera newtoniana.

e) A questão temporal em Lyell é forte, pois está fundamentado na metodologia indutiva e tem como amálgama a concepção de Herschel sobre a criação e o surgimento gradual das espécies. Lyell não encontrou evidências espaciais sobre a distribuição biogeográfica das espécies a partir de um preceito epigênico, assim como denotou grande enfoque para o papel do clima e dos rios no modelado do relevo, pois segundo Lyell, não havia encontrado evidências do papel das águas do oceano primário na modelagem da Terra. Lembremo-nos que não encontrar evidência, não significa que Lyell não acreditava nos postulados da criação, pois afinal, era um ferrenho defensor da causa vera e da hierarquia aristocrática da sociedade.

f) A questão espacial foi tratada inicialmente por Ratzel e por Huxley. Ratzel com forte influência no desenvolvimento da geografia humana, como apontado por Claval (1974) e Huxley (STODDART, 1986), por sua vez, fundamentou metodologicamente os estudos de geografia física, com forte impacto no ensino universitário inglês.

g) O que podemos tirar é que os modelos interpretativos em geografia física são epistemologicamente extremamente complexos levando-nos a refletir sobre a concepção de natureza que nos molda enquanto geógrafos. Por isso, acreditamos ser urgente o desenvolvimento de programas de pesquisa voltados para o estudo da história e da epistemologia da geografia física, pois em um mundo em que a natureza tornou-se raridade, novos padróes cognitivos e explicativos precisam ser construídos. Tal qual no tempo de Darwin, o mundo agora em mutação mais complexa e intensa, exige uma reflexão sobre a Terra e seus fundamentos filosóficos e metafísicos. Isso cabe, dentre as ciências sociais, à geografia realizar, pois, demonstrou ao longo de sua história, uma enorme e potencial riqueza conceitual e ontológica. 


\section{Referências}

ANDERSON, Owen. Charles Lyell, uniformitarianism, and interpretative principles. Zygon, 42(2), p. 449-462, 2007.

BACHELARD, G. A formação do espírito científico. RJ: Contraponto,1996.

BUENO-HERNANDEZ, Alfredo. \& LLORENTE-BOUSQUETS, Jorge. The other face of Lyell; historical biogeography in his Principles of Geology. Journal of Biogeography, 33, p. 549-559, 2006.

BLUMEMBACH, Johann Friedrich. Uber der Bildungstrieb. Gottingen, Johann Cristian Dietrich, 1781.

CASSIRER, Ernest. El problema del conocimento. Vol. IV, México, Fondo de Cultura Económica, 1993.

CAPEL, Horácio. Filosofía y ciencia en la geografía contemporánea. Barcelona, Temas Universitásrios, 1982.

CLAVAL, Paul. Evolucíon de la geografía humana. Madrid, Oikos-Tau, 1974.

DARWIN, Charles. A origem das espécies. SP, Hemus, 1981.

DESMOND, Adrian. \& MOORE, James. A vida de um evolucionista atormentado. Darwin. SP, Geração Editorial, 1995.

DEPEW, David J. Consequence etiology and biological teleology in aristotle and Darwin. Stud. Hist. Philo. \& Biomed. Sci., XXX, p. 1-12, 2008.

FALCON, A. Aristotle and the science of nature. Cambridge, Cambridge University Press, 2006.

GOETHE, Johann Wolfgang von. Die schriften zur naturwissenschaft. 21 vols, Weimer, Hermann Bohlaus Nachfolger, 1977.

Werke. 14 vols., Munich, C.H. Beck, 1988.

HAECKEL, Ernest. Les Merveilles de la vie. Études de philosophie biologique. Paris, Schleicher Fréres, 1904.

HERSCHEL, F. J.W. Physical geography of the globe. Edinburgh, Adam and Charles Black, 1861.

HODGE, Jonathan e RADICK, Gregory (orgs) The Cambridge companion to Darwin. Cambridge, Cambridge University Press, 2003.

KANT, Immanuel. Crítica da faculdade de julgar. RJ, Forense Universitária, 1995.

KEYNES, Richard. Aventuras e descobertas de Darwin a bordo do beagle. RJ, Jorge Zahar editor, 2004.

LAUDAN, Rachel. From mineralogy to geology. Chicago, Chicago University Press, 1987.

LENNOX, J. Darwin was a Teleologist. Biology and philosophy, 8, 1994, p.405-21.

LIVINGSTONE, David. The geographical tradition. Cambridge, Blackwell, 1992.

LYELL, Charles. Principles of geology. 2 vols, London, John Murray, 1832. 
MYERS, Ernest. The growth of biological thought. Cambridge, Harvard University Press, 1982. NIETZSCHE, F.W. Zur genealogie der moral.Berlim, Walter de Gryter, 1980.

RATZEL, Friederich. Antropogeografia. Turin, Fratelli Boca Editori, 1975.

RICHARDS, Robert J. The romantic conception of life. Chicago, Chicago University Press, 2002.

RUDWICK, M.J.S. The Strategy of Lyell Principles of Geology. Isis, 61, p. 1-41, 1970.

RUSE, Michael. Darwinism and Mechanism: Metaphor in Science. Stud. Hist. Phil.Biol.\& Biomed.Sci., 36, p. 285-302, 2005.

SECORD, James. Victorian sensations. Chicago, Chicago University Press, 2000.

STIX, Gary. O legado vivo de Darwin. Scientific American Brasil, ano 7, n. 81, p.26-31,2009.

STODDARDT, D.R. On geography. London, Blackwell, 1986.

VIRGILI, Carmina. Charles Lyell and Scientific Thinking in Geology. C.R. Geoscience, 339, p. 572-584, 2007.

VITTE, Antonio Carlos. Da ciência da morfologia à geomorfologia geográfica. Uma contribuição à história do pensamento geográfico. Mercator, 7, p. 10- 20, 2008.

WOOL, David. Charles Lyell - "the father of geology"- as a Forerunner of Modern Ecology. OIKOS, 94, p. 385-391, 2001.

Antonio Carlos Vitte - Professor do departamento de Geografia e do Programa de Pós-Graduação em Geografia, Unicamp, SP. 